\title{
O papel da translinguagem na Linguística Aplicada (in)disciplinar
}

\author{
The role of translanguaging in \\ (in)disciplinary Applied Linguistics
}

\author{
Maria Inêz Probst Lucena \\ Universidade Federal de Santa Catarina, Florianópolis, Santa Catarina, Brasil
}

\begin{abstract}
Resumo: Este ensaio está inserido no debate sobre o papel da Linguística Aplicada (in)disciplinar na produção de saberes sobre a vida social contemporânea. Discuto como o conceito de translinguagem pode nos ajudar a questionar entendimentos dominantes sobre bilinguismo e uso da linguagem em um mundo no qual somos desafiados a entender novos modos de comunicação. Argumento que a abordagem translíngue permite que avancemos na discussão teórico-analítica de práticas linguísticas do século XXI e para elaborar esta discussão, além da experiência em empreitadas etnográficas que oferecem a compreensão do campo aplicado, apoio-me em dois textos. Uma foto de uma propaganda de uma rede nacional de curso de idiomas e um pôster de uma campanha política. O primeiro contribui para ilustrar a invisibilidade da complexidade sociolinguística brasileira e o segundo contribui para ilustrar como a mobilidade de pessoas nos desafia a compreender a contingência social, cultural, histórico e política de práticas comunicativas.
\end{abstract}

Palavras-chave: Linguística Aplicada; Translinguagem; Práticas comunicativas contemporâneas

\begin{abstract}
This essay draws upon the theoretical frameworks on the role of (in)disciplinary Applied Linguistics in producing knowledge about contemporary social life. I discuss how the concept of translanguaging can help us to question dominant understandings of bilingualism and language use in a world in which we are challenged to understand new modes of communication. I argue that the translingual approach allows us to advance theoretical/analytical discussions on linguistic practices in the 21 st century. My arguments are based on ethnographic experiences and on two particular texts. The first is a photo of an advertisement for a well- known language course organization, and the second is a political campaign poster. The first example helps to illustrate the lack of awareness of sociolinguistic complexities in Brazil, and the second illustrates how the mobility of people challenges us to understand the social, cultural, historical, and political contingency of communicative practices.
\end{abstract}


Keywords: Applied Linguistics; Translanguaging; Contemporary communicative practices

\section{A LA (in)disciplinar e a vida social contemporânea}

Neste ensaio, inserido no debate sobre o papel da Linguística Aplicada (in)disciplinar (MOITA LOPES, 2006) na produção de saberes sobre a vida social contemporânea, discuto como o conceito de translinguagem ${ }^{1}$ pode nos ajudar a questionar entendimentos dominantes sobre bilinguismo e uso da linguagem em um mundo no qual somos desafiados a entender novos modos de comunicação. Argumento que a abordagem translíngue permite que avancemos na discussão teórico-analítica acerca do entendimento de práticas linguísticas do século XXI, destacando como o termo translinguagem está relacionado com entendimentos do prefixo Trans, apresentados por linguistas aplicados críticos brasileiros. Além da experiência em empreitadas etnográficas, apoio-me em dois textos que sustentam e ilustram a discussão. Uma foto de uma propaganda de uma rede nacional de curso de idiomas e um pôster de uma campanha política. O primeiro contribui para mostrar a invisibilidade da complexidade sociolinguística brasileira e o segundo contribui para mostrar como a mobilidade de pessoas nos desafia a compreender a contingência social e política de práticas comunicativas que se constituem mais e mais de modo fluido, híbrido e criativo. Esses aspectos peculiares de comunicação multilíngue são também registrados nos nossos estudos do campo aplicado.

A Linguística Aplicada (LA) brasileira em sua vertente (in)disciplinar tem desenvolvido reflexões críticas sobre como a educação linguística é pautada em uma lógica monolíngue e em princípios de homogeneidade linguística. Reflexões acadêmicas de pesquisadores brasileiros, contidas em publicações seminais das décadas de 80, 90 e 2000 (CAVALCANTI, 1999; SIGNORINI, 1998, 2002, 2006, 2018; MOITA LOPES,

\footnotetext{
${ }^{1} \mathrm{O}$ termo translanguaging tem sido traduzido e utilizado de diferentes formas no Brasil (por exemplo, 'translinguismo' em Guerola (2017) e 'translinguajamento' em Oliveira; Nascimento (2017). Opto por translinguagem, por entender que subjacente a esta tradução está a ideia de deslocamento social de noções pré-concebidas de linguagem. Busco evidenciar nesse termo a "linguagem no mundo" (SIGNORINI, 2018, p. 66), reconhecida a partir do "mundo dos usuários da linguagem ordinária" (RAJAGOPALAN, 2008, p. 37) e que traz subjacente um vasto campo de saber popular do campo aplicado, especialmente quando tratamos de contextos sociolinguísticos minoritários. Alinho-me ainda à decisão de Yip e García (2018) que optaram também por essa tradução "aportuguesada" por razões de padronização estética e de maior acessibilidade.
}

Revista da Anpoll, Florianópolis, v. 52, n. 2, p. 25-43, jun.-out., 2021 | 26 
2006; 2013b; SCHLATTER; GARCEZ, 2012) contribuíram para o interesse de voltarmos o foco das investigações para a exclusão das minorias e de grupos marginalizados. Pesquisas do campo aplicado no Brasil passaram a incluir em suas agendas, desde os anos 80 , estudos voltados para a linguagem no modo como ela é utilizada em diferentes práticas sociais e contribuíram para visibilizar fronteiras linguísticas e culturais. Distanciados de modelos de ensino de línguas e de pedagogias hegemônicas dominantes, de uma visão reducionista de cultura e de "lógicas solucionistas" (MOITA LOPES, 2006, p. 20), esses estudos vêm buscando mostrar como indivíduos se envolvem, mais e mais, em modos de socialização a partir da fluidez e hibridismo de formas linguísticodiscursivas, construídas com base em redes transnacionais, redes transculturais, redes digitais etc. Nesse sentido, a LA (in) disciplinar brasileira tem contribuído, sobremaneira, para diferentes tipos de reflexões e críticas acerca de pressupostos pautados em uma visão de língua enquanto objeto fixo e estático.

Preocupada em discutir a realidade heteroglóssica do Brasil, a LA tem tido um papel relevante em relação a iniciativas de resistência e luta no sentido de "mudar/moldar a ecologia linguística do nosso país" (MAHER, 2013, p. 128). Em oportunas discussões, a ideia de uma língua nacional e de normatização linguística tem sido questionada. A complexidade sociolinguística, a criatividade, a riqueza, a complexidade social e as diferenças culturais são discutidas por pesquisadores que vêm destacando há quase duas décadas as práticas comuns de usos da língua que, em sua maioria, seguem “princípios dinâmicos de desregulamentação de uma dada ordem linguística" (SIGNORINI, 2002, p. 93).

\section{Limites utópicos: o mito do Brasil como nação monolíngue}

A preocupação em visibilizar a complexidade sociolinguística brasileira justifica-se pela lógica da homogeneidade linguística que ainda prevalece fortemente no país. Mediatizase e cultiva-se o mito de nação monolíngue (CAVALCANTI; BORTONI-RICARDO, 2007), por meio de ideias utópicas de comunidade homogênea (PRATT, 2013[1987]) que inventam e sustentam a noção de que o Brasil é um país monolíngue. O exemplo, mostrado, a seguir, na Figura 1, de anúncio de uma rede de idiomas exposto em outdoors em grandes cidades brasileiras, ajuda a dimensionar o desafio de se falar de práticas 
comunicativas heterogêneas no Brasil. A publicidade do curso, ao anunciar que pode transformar o Brasil em um país bilíngue, ao oferecer o ensino de Inglês, Espanhol, Italiano, Japonês, Chinês, Alemão, Francês, assume uma perspectiva hegemônica do conceito de língua e invisibiliza os recursos linguísticos e semióticos de indígenas, das pessoas surdas e de quilombolas, além das variedades do português que fazem parte do repertório de cidadãos brasileiros, em zonas rurais e urbanas.

Figura 1 - Outdoor com anúncio de rede de escola de idiomas

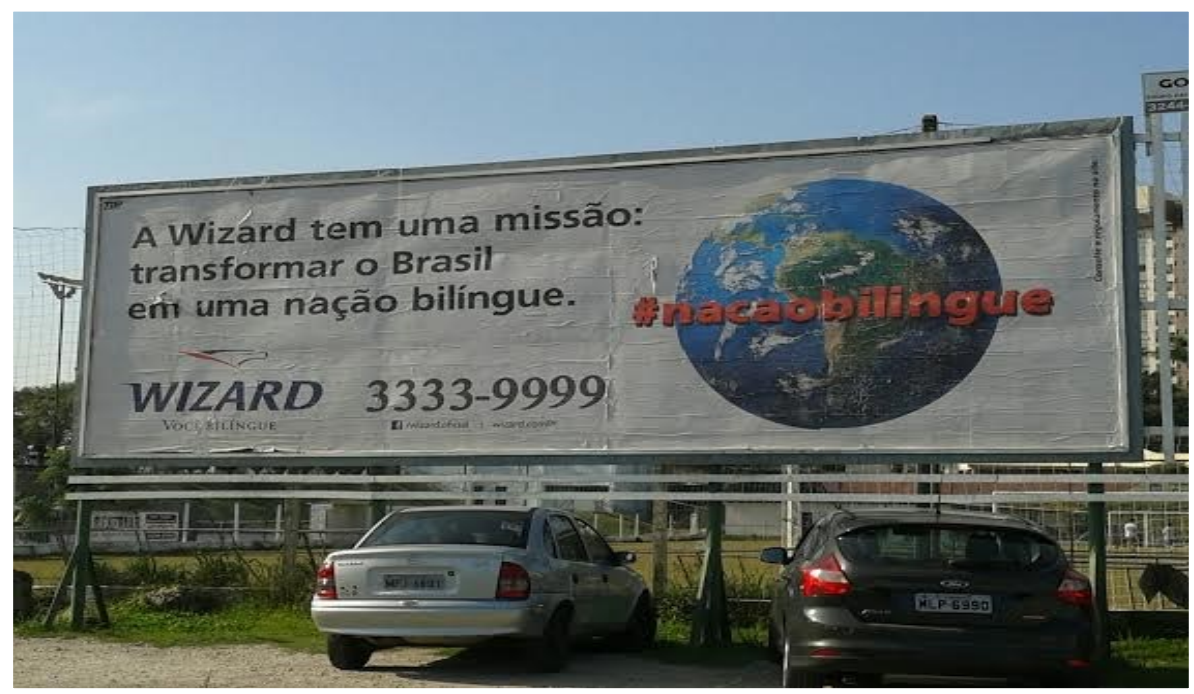

Fonte: Autora, agosto de 2014

No entanto, embora reforçados pela grande mídia e pelo senso comum, esses entendimentos dominantes têm sido questionados. Não só no Brasil as ordens socioculturais e linguísticas mundiais desestabilizam a ordem diglóssica tradicional. Mais e mais, em um mundo em que a linguagem é utilizada em combinações complexas, somos desafiados, especialmente na educação de línguas, a dar conta de modos de comunicação que desestabilizam entendimentos dominantes. Nas últimas décadas, transformações sem precedentes, geradas pelos processos de globalização geocultural, afetaram as sociedades em todo o planeta. Limites modernos de tempo e espaço foram alterados, potencializando a mobilidade e os contatos entre pessoas, mensagens, tecnologias e recursos comunicativos que, se de alguma forma sempre existiram, na modernidade recente tornaram-se inéditos em sua intensidade, rapidez e abrangência. Essas transformações vêm exigindo de nós o entendimento de novas formas de apropriação da língua entre 
diferentes grupos (PRATT, 2013 [1987]). Demandam-nos o entendimento de como a linguagem desafia estruturas sociais, uma vez que é regulada pelos contextos existentes de relações de poder e de como a linguagem, livre de autoritarismos pode ser uma promessa de diálogos mais democráticos, em um mundo onde os espaços de diálogo requeridos para uma democracia forte estão, dia a dia, desaparecendo.

\section{Novas possibilidades teórico-analíticas: A translinguagem como resposta à demanda sociocultural e política}

Para dar conta dessa mobilidade e complexidade linguística e cultural do mundo contemporâneo, insights teóricos provenientes dos estudos do campo aplicado e da crítica em relação à linguística moderna geraram a necessidade de "repensar nosso aparato conceitual e analítico" 2 (BLOMMAERT, 2010, p. 1). Nessa perspectiva, grande quantidade de termos ${ }^{3}$ têm sido utilizados por diferentes autores, de acordo com seus contextos e objetos de pesquisa. E para buscar entendimentos sobre o bilinguismo, sobre a hibridização cultural e sobre a mobilidade em um tempo/espaço mais e mais interconectado globalmente (MOITA LOPES, 2013; SIGNORINI, 2013; BORTOLINI; GARCEZ; SCHLATTER, 2013) as discussões têm assumido a intenção de captar com maior precisão as dinâmicas culturais, sociais, políticas e históricas das práticas comunicativas humanas. Ou seja, buscam entender o uso de recursos linguísticos móveis e heterogêneos "enquadrados em termos de redes, fluxos e movimentos transcontextuais" 4 na complexidade de práticas linguísticas do século XXI (BLOMMAERT, 2010, p. 1).

Entre os vários termos e conceitos que têm surgido para explicar as novas formas de comunicação, considero translinguagem o que melhor nos ajuda a apreender o que significa ser bilíngue ${ }^{5}$ no mundo atual. Trazendo o foco para o cenário brasileiro e para

\footnotetext{
${ }^{2}$ No original: rethink our conceptual and analytic apparatus.

3 Por exemplo: 'Translanguaging' (GARCÍA, 2009; GARCÍA; WEI, 2014); 'práticas translíngues' (CANAGARAJAH, 2013); 'transidiomatic practices' (JACQUEMET, 2005); 'truncated multi-lingualism' (BLOMMAERT, 2009); ‘codemeshing (YOUNG, 2004); 'flexible bilingualism' (CREESE; BLACKLEDGE, 2010); 'heterolingualism' (PRATT, 2013n); 'metrolingualism' (PENNYCOOK, 2010), para citar alguns.

${ }^{4}$ No original: framed in terms of trans-contextual networks, flows and movements.

${ }^{5}$ Alinhada com Garcia, utilizo os termos bilíngue e bilinguismo como termos que implicam uma visão que vai além de "um mais um igual a dois" (GARCIA, 2009, p. 5), uma visão plural que implica o uso fluido
} 
os estudos do campo aplicado, entendo que a abordagem translíngue oferece possibilidades teórico-analíticas que nos permitem discutir o "caráter híbrido e mestiço" (MOITA LOPES, 2006, p. 100) tão presente na agenda da área. A reavaliação de práticas linguísticas, sob as lentes da translinguagem, permite o seu entendimento além de um enquadre normativo, fixo e monolíngue. Antes de serem avaliadas como deficitárias e desviantes, as práticas passam a ser compreendidas como estratégicas e criativas sempre que utilizadas com propósito claro de responder aos desafios e mudanças trazidas pela diversidade, pela tecnologia e pela mobilidade em contextos específicos.

Diferentemente, portanto, de uma "pluralização do monolinguismo" 6 (PENNYCOOK, 2010, p. 12), ou de práticas que resultam em "monolinguismos paralelos" 7 (HELLER; McELHINNY, 2017, p. 113), translinguajar não significa somente alternar códigos, uma vez que os falantes, com base na perspectiva da translinguagem, não mudam simplesmente de língua, alternando códigos monolíngues separados. Ao translinguajar, falantes levam a cabo suas intenções comunicativas, utilizando recursos de seus repertórios linguísticos e a compreensão política e histórica de que têm de seus mundos bilíngues. Os recursos linguísticos e semióticos permitem que os sujeitos concretizem ações que são de importância pessoal e coletiva, em um mundo onde o fluxo e o hibridismo de culturas e de línguas são a norma (GARCÍA, 2009). Pensada a partir da ideia de que os falantes possuem um sistema linguístico único, heterogêneo e complexo, a concepção de translinguagem se diferencia da concepção tradicional de code-switching ${ }^{8}$. Enquanto, na concepção de code-switching, línguas são enumeradas e compreendidas como códigos separados e não interativos, a translinguagem afasta a ideia de um sistema dualista e assume o sistema linguístico como unitário. Assim, ao contrário de uma visão psicolinguística, em que dois sistemas (ou mais) de línguas, conforme socialmente nominadas, são usados em momentos diferentes durante a comunicação, a perspectiva da translinguagem aponta para um sistema único. A partir desse sistema único, composto por um vasto repertório linguístico, os bilíngues lançam

do repertório linguístico de um falante que são acessados para tornar a comunicação socialmente significativa.

${ }^{6}$ No original: pluralization of monolingualism.

${ }^{7}$ No original: parallel monolingualisms.

${ }^{8}$ Code-switching refere-se ao uso, ora de uma língua, ora de outra (conforme elas são socialmente nomeadas) em uma mesma fala. Ou seja, o conceito parte de uma perspectiva dualista, em que o falante faz troca entre um sistema e outro (GARCÍA, 2009).

Revista da Anpoll, Florianópolis, v. 52, n. 2, p. 25-43, jun.-out., 2021 | 30 
mão dos recursos das línguas em seus usos situados. O acesso a esses recursos depende de valores culturais e do espaço em que acontece a comunicação e pode-se dar de forma dinâmica, em um continuum sem fronteiras definidas entre uma e outra língua, conforme elas foram convencionalmente e socialmente nominadas (GARCÍA; WEI, 2014; OTHEGUY; GARCÍA; REID, 2019).

O entendimento do modo como se dá a geração de práticas de linguagem sob a perspectiva translíngue é, portanto, muito pertinente para a LA. Nessa visão, os métodos analíticos abarcam todos os recursos utilizados na comunicação e procura-se entender as práticas em suas complexidades, no modo como elas são geradas pelos falantes (GARCÍA; WEI, 2014). Sendo assim, essa perspectiva é uma boa candidata a uma teoria de línguas (WEI, 2019), pois, ao considerar o modo como o falante aciona seu sistema linguístico, a translinguagem reconhece práticas diversas e os cenários sócio-históricos em que elas acontecem (WEI, 2018). A formação do sistema linguístico - compreendido por García e Wei como um sistema formado por trans-sistemas semióticos, criados em trans-espaços - permite que "novas práticas de linguagem, práticas multimodais significativas, subjetividades e estruturas sociais $\mathrm{s}[\mathrm{ejam}]$ dinamicamente geradas em resposta às complexas interações do século 21" (GARCÍA; WEI, 2014, p. 43). Assim, a habilidade que os indivíduos têm de potencializar seus recursos linguísticos-semióticos contribui para a construção de sentidos e para a transformação contínua desses recursos.

Para ilustrar a discussão sobre como as práticas de linguagem vão se desenvolvendo de acordo com os saberes de mundo, exigidos nas relações e nas interações de pessoas que fazem parte de diferentes universos que constituem suas identidades bilíngues, apresento um cartaz da campanha para deputada de uma jovem liderança política dos Estados Unidos (Figura 2), Alexandra Ocasio-Cortez.

No cartaz em análise, a comunicação se dá com o auxílio de "ricos e complexos recursos comunicativos" ${ }^{10}$ (GARCÍA; WEI, 2014, p. 32), com escolhas abstratas e complexas, cujo "processo de criação de signos, e o processo de interpretá-los, é um

\footnotetext{
${ }^{9}$ No original: new language practices, meaning - making multimodal practices, subjectivities and social structures are dynamically generated in response to the complex interactions of the 21st century.

${ }^{10}$ No original: rich and complex communicative resources.
} 
processo de translinguagem em que estão envolvidas palavras, imagens, símbolos e cores, todos eles culturalmente e historicamente específicos e significativos" ${ }^{\prime 11}$ (p. 34).

Figura 2 - Cartaz de propaganda eleitoral dos EUA.

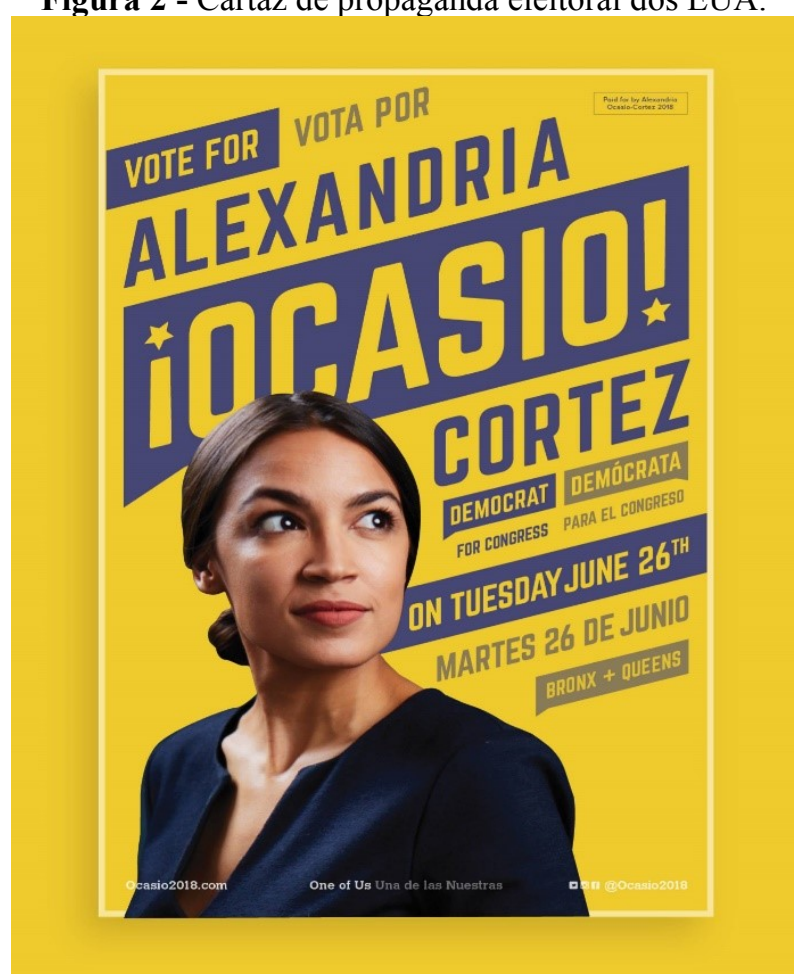

Fonte: https:/www.vox.com/policy-and-politics/2018/7/2/17519414/ocasio-cortez-campaign-designcampaign-posters-tandem-branding. Acesso em: maio 2019

Em 2018, Alexandria Ocasio-Cortez, filha de uma imigrante porto-riquenha, foi eleita para o congresso norte-americano e se transformou na mulher mais jovem a ocupar uma cadeira naquele espaço. Nascida no Bronx, ela cresceu naquela área, uma das mais pobres e repletas de desafios sociais de Nova York. Alexandria e sua equipe fizeram uma campanha cuja estratégia trouxe à tona a criatividade e a liberdade com que a linguagem pode ser usada, usando recursos comunicativos do mundo moderno. Seu modo de fazer campanha abriu um importante espaço de diálogo, tão requerido para a democracia no cenário estadunidense. Ainda que desenvolvida em uma perspectiva de bilinguismo dualista, com os enunciados aparecendo em espanhol e inglês (Democrat for congress/demócrata para el congresso - one of us/una de las nuestras), a iniciativa quebrou paradigmas monolíngues, uma vez que, nos EUA, geralmente, em enunciados

\footnotetext{
${ }^{11}$ No original: [the] process of creating these signs, and the process of interpreting them, is a process of translanguaging, involving words, images, simbols and colors, all of which are culturally and historically specific and significant
} 
políticos durante a campanha, não é utilizada outra língua além do inglês. Além disso, o nome de Ocasio aparecia entre pontos de exclamação, com o marcador prosódico em sua forma invertida, conforme usado na grafia em espanhol e trazia uma estrela em sua composição, numa referência à bandeira porto-riquenha. Esse recurso semiótico no ponto de exclamação trouxe ainda mais a identidade da candidata para a cena política, aproximando-a da grande população de hispanofalantes de Nova York. Na grande imprensa, a campanha foi reconhecida como inspirada em valores sociais e com inclinação para justiça social (BUDDS, 2018). O exemplo foi trazido aqui especialmente para enfatizar que o entendimento do significado destes signos requer a compreensão não somente da estrutura linguística, mas também das outras pistas linguísticas, políticas e culturais que juntas compõem os signos. Ou seja, a campanha política, em análise aqui, mostra como a mobilidade de pessoas nos desafia a compreender a comunicação com base na interconectividade de signos, na ressemiotização e na reinscrição de imagens (GARCÍA; WEI, 2014).

A habilidade requisitada em exemplos como este da campanha de Ocasio-Cortez implica na necessidade, apontada na abordagem translíngue de o falante potencializar, transformar e ressignificar o repertório linguístico-semiótico de acordo com a situacionalidade da ação comunicativa. Instiga investigações avessas a generalizações e enfatiza a necessidade do olhar para o idiossincrático, para o particular, para o uso situado da linguagem. Essas características da translinguagem respondem às demandas epistemológicas da LA brasileira, que tem buscado modos de pesquisa que tragam "outro discurso [...], que se abr[a] para outras teorizações sobre língua e linguagem” (MOITA LOPES, 2013a, p. 20) e que respondam as "questões dos tempos que vivemos" (p. 37).

Atendendo a necessidade de atenção aos conflitos existentes em interações multilíngues, a abordagem translíngue questiona ideias de pluralismo harmônico e busca reavaliar práticas linguísticas e padrões comunicativos considerados deficitários diante de um padrão nacional sem, no entanto, romantizar as práticas. Ou seja, as práticas não podem ser avaliadas sem que sejam também considerados os conflitos e interesses particulares, em cada cenário. Nesse sentido, a abordagem pode ser emancipatória, já que compreende diferentes práticas de linguagem. Mas há que se evitar extremos e análises simplistas que excluam a análise de detalhes socioculturais, políticos e históricos envolvidos nos usos linguísticos, específicos, de campos situados. 
O conceito de translinguagem, em meio a essas discussões, atende à demanda de uma virada sociocultural e política, conforme vislumbrada pela LA no Brasil, desde os anos 90. Atende ainda à demanda pelo avanço das indagações sobre multilinguismo e mobilidade, descentralizadas do modelo que orientam teorias monolingues.

Como destaca Signorini, em trabalho recente, o ato de desfazer

\begin{abstract}
equacionamentos já dados, tanto pela desconstrução e re-entextualização de 'velhos conceitos' quanto pela experimentação e criação de novos têm trazido para o campo aplicado dos estudos da língua(gem) desenvolvidos no Brasil o desafio de se buscarem novas soluções para velhos problemas de modos mais produtivos no sentido também de menos excludentes ou discriminatórios, conforme apontado em discussões críticas de teorias e modelos calcados no monolinguismo monoglóssico (SIGNORINI, 2018, p. 667).
\end{abstract}

Importa, no entanto, dizer aqui que a intenção da utilização de novos conceitos não significa "começar de novo, a partir do zero", tampouco propor uma discussão sobre uma "genuína virada científica da linguagem”, para usar os termos de Rajagopalan (2008, p. 30) ao refletir sobre discursos leigos e especializados sobre o objeto língua.

O pressuposto colocado aqui é que o conceito de translinguagem coincide com as orientações epistemológicas que guiam os estudos do campo aplicado, cujas preocupações incluem o entendimento da linguagem no "mundo de mobilidade, de redes digitais, de fronteiras esmaecidas de estados-nação, de inseguranças, de ambiguidades, de desessencializações identitárias e linguísticas, de superdiversidade" (MOITA LOPES, 2013a, p. 19). Na educação de línguas, coincide com a nossa necessidade, enquanto educadoras, de discutirmos as salas de aulas e a pedagogia de línguas sem um controle nacionalista, sem o monolinguismo como uma dimensão importante para o funcionamento da nação e sem a recompensa por performances monolíngues. Coincide, portanto, com a necessidade de adoção de uma teoria sociolinguística que enfatiza a diversidade e que a entende como recurso e que questiona e critica a linguagem enquanto um objeto delimitado e fixo (HELLER; McELHINNY, 2017).

O prefixo trans, utilizado na abordagem translíngue no sentido de ampliação, de transcendência, de ir além, coincide com suas definições apresentadas por linguistas aplicados críticos brasileiros que buscavam, nas décadas anteriores, entender "o debordamento de fronteiras entre as línguas" (ASSIS-PETERSON; COX, 2007, p. 42). Há mais de uma década, portanto, as autoras destacavam a necessidade de se "inventar 
um conceito que agarr[asse] a vida de uma língua em seu estado de fluxo, que nos permit[isse] pensá-la como líquido e não como sólido" (p. 42). Ao discutir o conceito de transculturalidade, Assis-Peterson e Cox enfatizavam que o prefixo trans poderia dar conta das "contaminações" e ser capaz de "traduzir [as] realidades dos mundos mesclados" (ASSIS-PETERSON; COX, 2007, p. 35).

Uma década após, o prefixo ainda é pauta em discussões da LA. Em estudo recente, Monte Mor (2017) retoma a discussão e faz uma revisão acerca do radical trans, e também de multi e pluri com base em Pennycook (2010), Canagarajah (2013) e Cavalcanti; Bortoni-Ricardo (2007). Seguindo a linha desses estudos, a autora ressalta que o radical trans no termo transculturalidade contribui para a discussão sobre hegemonia cultural; sobre transgressão e o fluxo percebido nas interações culturais, linguísticas e sociais, bem como para a compreensão de línguas e linguagem e na negociação da construção de sentidos. No entanto, cabe destacar que, embora Monte Mor concorde com as posturas dos autores acima citados, referentes às discussões sobre igualdade, sobre promoção de oportunidades e sobre pertencimentos, ela destaca sua posição contrária a um binarismo, cujos paradigmas evidenciam o 'trans' ou o 'multi' e excluem o que é considerado 'mono' ou 'uni'. Segundo a autora, não sendo “estes últimos a regra, eles podem ser um recurso didático para se ter uma das possíveis compreensões sobre um dos vários tipos de sistema" (MONTE MOR, 2017, p. 13).

Recorrentemente demandado na LA (in)disciplinar, estudos transculturais têm deslocado nossos pontos de vista de estudos variacionistas atrelados à norma ou dela derivados. Para fins da presente discussão, importa destacar que os aspectos teóricos que pautam os estudos transculturais, embora apresentem especificidades, dependendo da linha teórica em que se inserem, buscam uma educação linguística condizente com a realidade proporcionada pela mobilidade recente, discutem o envolvimento com novas formas de cultura popular e consideram as relações assimétricas de poder. Esses aspectos, conforme apontado por diferentes pesquisadores, são muitas vezes minimizados e pouco discutidos em estudos linguísticos (BLOMMAERT, 2010; GARCÍA, 2009; MENEZES DE SOUZA, 2011; HELLER; McELHINNY, 2017; GARCEZ, 2018; SIGNORINI, 2018). 


\section{A contribuição da translinguagem para os estudos do campo aplicado}

Por nos permitir ir além, o conceito de translinguagem (ainda que não resolva todos os problemas impostos pela lógica monolíngue), ajuda-nos a abordar o modo como perspectivas de educação linguística baseadas em ideais utópicos de comunidades homogêneas podem ser excludentes e discriminatórias. Por exemplo, em uma discussão sobre a realidade heteroglóssica do Brasil, Signorini explica como as fronteiras linguístico-culturais estabelecidas com base na ideia de uma língua nacional e da normatização linguística conflitam com a ordem no campo situado. A autora argumenta que a invisibilização da complexidade sociolinguística gera a marginalização, esconde a criatividade, a riqueza, a complexidade social e as diferenças culturais encontradas nas práticas comuns de usos da língua. Com base em um purismo socialmente construído, sem apoio na realidade e situacionalidade dos usos linguísticos, metadiscursos hegemônicos definem e regulam o que é certo e errado no uso da língua sem que as (SIGNORINI, 2002). Assim, pensando no ensino, a translinguagem contempla mais uma demanda da LA que é a observação sistemática do uso da língua a partir da vivência cotidiana em cenários onde a

perturbação trazida pela variação é o que permite ao falante/escrevente se constituir enquanto agente que tanto reproduz formas e sentidos, papéis e identidades, quanto os altera, tensiona, torce, subverte e produz o novo, seja ele percebido como criativo, revolucionário, ou apenas como descabido, torto, mal enjambrado" (SIGNORINI, 2002, p. 93).

$\mathrm{Na}$ educação de línguas, portanto, tal regulamentação está relacionada com o modelo de bilinguismo adotado nos espaços escolares. Por exemplo, subjacente à ideia do bilinguismo aditivo bastante reconhecido e legitimado no Brasi1 ${ }^{12}$, há uma separação clara entre as línguas envolvidas. No ensino bilíngue, organizado com base nesse modelo, esses programas compartimentalizam o uso das duas [ou mais] língua, que são ministradas, geralmente, em momentos diferentes e por professores diferentes. Nesse caso, o monolinguismo em cada uma delas mantêm-se como norma, cada qual como um sistema autônomo que, segundo essa perspectiva, pode ser acessado em momentos diferentes. Tal visão compartimentalizada do uso das línguas pode trazer "efeitos

\footnotetext{
12 Para uma discussão de modelos de bilinguismo, ver Maher (2007) e García (2009).
} 
perniciosos para os alunos em práticas educacionais"13 (OTHEGUY; GARCÍA; REID, 2019, p. 625), uma vez que a norma legitimada em cenários escolares, via de regra, privilegia grupos de línguas maioritárias.

Nesse sentido, a abordagem translíngue contribui para a teoria da desregulamentação linguística e nos ajuda a explicar o modo como os falantes se movimentam no contínuo das línguas que utilizam, de acordo com padrões da comunidade, do lar e da escola (GARCÍA; WEI, 2014) que categorizam os usos linguísticos em “(in)comum, (in)desejável, (i)legítimo, (in)correto, etc.” (SIGNORINI, 2002, p. 94).

Alinhada, portanto, com a proposição teórica da LA em criar inteligibilidades sobre o uso da linguagem nos estudos do campo aplicado, a translinguagem pode contribuir para uma pedagogia transformadora (GARCÍA; WEI, 2014) ao destacar possibilidades de resistência por parte dos falantes nas práticas comunicativas (LUCENA; CAMPOS, 2018).

Com base em reflexões provenientes de diferentes estudos (CARDOSO, 2014; GRUEUL, 2018; REIS, 2021; SOUSA, 2021, para citar alguns) desenvolvidos no grupo de pesquisa Educação linguística e pós-colonialidade, coordenado por mim, entendo que a translinguagem pode contribuir para expandir o debate e a crítica em relação aos estudos da linguagem. Pode também contribuir para problematizar perspectivas apolíticas de pedagogia de línguas e questionar padrões comunicativos analisados em relação à língua nacional, dominante e padronizada. Embora os dados e resultados dos estudos do grupo não serão discutidos aqui, por questão de espaço, importa destacar que eles têm desnudado episódios em que práticas translígues são estrategicamente utilizadas em contextos educacionais, na tentativa de lidar com a produção de significados alternativos na busca de justiça social e que importam, sobremaneira, para pensarmos como ideologias linguisticas sustentam conceitos como como "domínio pleno da escrita" (SIGNORINI, 2001, p. 105), associado ao domínio de "padrões de teorização e avaliação prestigiados em instituições escolares e acadêmicas" (p. 98) identificados como a norma. Pedagogicamente, entendo que as discussões acerca da abordagem translíngue demandam a promoção de planejamentos de ensino de línguas para além do viés nacionalista e monolíngue, que busca, com base em um aparato estatal, perpetuar o controle e manutenção de fronteiras linguísticas. Na sala de aula, a vida pedagógica evoca a compreensão das realidades sociais de sujeitos e o uso de recursos linguísticos que

\footnotetext{
${ }^{13}$ No original: pernicious effects in educational practices.
} 
escapam 'de caixas' que os orientam a selar suas línguas, hermeticamente, em sistemas linguísticos separados. Em contraponto, como mostram dados de estudos de nosso grupo de pesquisa, brasileiros descendentes de russos (CAMPOS, 2015), imigrantes procedentes do Haiti (GREUEL, 2018) e indígenas de diferentes etnias (GUEROLA, 2017) aparecem como agentes sociais que interagem, resistem e (re)criam significados em seus mundos, buscando sair dessas 'caixas' negociando, ainda que nem sempre com facilidade, culturas, línguas e identidades.

São, portanto, estudos da linguagem que envolvem a complexidade social, cultural e política das relações sociais e que orientam nossos olhares para o modo como sujeitos lidam com as configurações locais e com as ações nas quais eles atuam. Procuramos avançar na discussão sobre a pedagogia de línguas, deslocando-nos de inscrições fixas, o que possibilita que enfoquemos aspectos que expliquem as diferenças como criatividade e riqueza linguística (BLOMMAERT; RAMPTON, 2011). Desse modo, entendo que a ideia de reaproximação da linguagem com o mundo real, tão difundida na Linguística Aplicada e em suas discussões acerca da transculturalidade, está contemplada na dimensão social e histórica da abordagem translíngue, o que contribui para que as discussões sobre multilinguismo e mobilidade sociolinguística sejam ampliadas.

\section{Considerações finais}

Defendi aqui que a posição política estabelecida na visão translíngue coaduna com os princípios indisciplinares, transculturais e transdisciplinares demandados pela LA (in) disciplinar. Procurei mostrar que, longe de evocar modos de ação e de produção de saberes distanciado de questões históricas, políticas e econômicas, a perspectiva translíngue aborda o papel da linguagem em uma perspectiva de diversidade linguística compreendida na vida social contemporânea. Ressaltei como a discussão sobre transculturalidade (ver CAVALCANTI; BORTONI- RICARDO, 2007) se mantém presente e é coerente com a perspectiva translíngue, servindo de importante suporte para evidenciar conflitos e dificuldades encontradas em dinâmicas de poder, história e economia que estão envolvidos na relação linguagem e transformação social.

Ressalto, no entanto, que convém ter prudência com a celebração de novos paradigmas, como é o caso, por exemplo, da translinguagem. Sem defender a ideia de um plurilinguismo harmônico, que pode correr o risco de ser celebrado excessivamente (HELLER; McELHINNY, 2017) e sem querer romantizar as práticas multilíngues na 
Linguística Aplicada Brasileira, a menos que elas sejam devidamente problematizadas, juntamente com outros pesquisadores (PENNYCOOK, 2010; HELLER; McELHINNY, 2017, entre outros), entendo que os novos fenômenos do uso da linguagem na sociedade requerem a compreensão aprofundada e muitoa cautela. Como Heller e McElhinny (2017, p. 240) nos chamam a atenção, muitos "discursos benignos de variação" 14 podem invocar a diferença sem o comprometimento com a justiça social. Embora considerando importante o uso da abordagem translíngue como categoria heurística, não podemos correr o risco de conferir-lhe já o estatuto de teoria completa que pode ser aplicada a todo e qualquer cenário (PENNYCOOK, 2016). Em estudos sobre o tema, talvez seja o caso de investigarmos o que há para ser celebrado e o que há para ser problematizado.

$\mathrm{Ou}$ seja, a translinguagem não pode ser compreendida como uma categoria previamente imposta. Em nossos estudos etnográficos a prática tem sido discutida a partir da análise das interações, conforme elas vão naturalmente aparecendo. Assim, epistemologicamente, acredito que a etnografia pode impulsionar e fundamentar, de modo mais apropriado, nossa tentativa de entender os aspectos culturais, históricos e econômicos que perpassam a discussão sobre esses modos de ação e de usos dos recursos linguísticos.

A translinguagem parece contribuir para que alunas/os criem modos e caminhos alternativos e mais acessíveis a elas/es. Ou seja, na discussão centro-periferia, a abordagem translíngue pode nos ajudar a compreender como bilíngues e grupos minoritarizados criam e legitimam novos espaços discursivos em sua luta para garantir cidadania e modos de viver todas suas experiências (GARCÍA; WEI, 2014). Podemos discutir, sob essa perspectiva, o posicionamento metassociolinguístico dos falantes e como seus usos linguísticos são realinhados diante de validações hegemônicas acerca do que é correto/ incorreto, válido/inválido nos espaços específicos em que se encontram.

Assim, o conceito de translinguagem pode nos ajudar a entender os usos dos recursos linguísticos a partir de uma abordagem que considero substancialmente crítica. Pode nos ajudar a evitar julgamentos de usos dos recursos linguísticos de acordo com práticas linguísticas previamente rotuladas como erradas ou ilegítimas. Pode nos deslocar da perspectiva de monolinguismo paralelo e de estratégias que gerenciam e que controlam a diversidade e pode contribuir para o entendimento da diversidade a partir de microcaracterísticas de cenários situados, especialmente os periféricos, contribuindo para

\footnotetext{
${ }^{14}$ No original: discourses of benign variation.
} 
que a Linguística Aplicada se efetive ainda mais como campo de pesquisa para a produção de saberes sobre a vida contemporânea.

\section{Referências}

ASSIS-PETERSON, Ana Antônia; COX, Maria Ines Pagliarini. Transculturalidade e transglossia: para compreender o fenômeno das fricções linguístico-culturais em sociedades contemporâneas sem nostalgia. In: CAVALCANTI, M.; BORTONIRICARDO, S. M. (orgs.) Transculturalidade, linguagem e educação. Campinas: Mercado das Letras, 2007.

BORTOLINI, Letícia Soares; GARCEZ, Pedro de Moraes; SCHLATTER, Margarete. Políticas linguísticas e identidades em trânsito: espanhol e português em um cotidiano comunitário escolar uruguaio na fronteira com o Brasil. In: MOITA LOPES, L. P. O Português no Século XXI: Cenário Geopolítico Brasileiro. São Paulo: Parábola. 2013. p. 249- 273.

BLOMMAERT, Jan. The sociolinguistics of globalization. Cambridge: Cambridge University Press, 2010.

BLOMMAERT, Jan; RAMPTON, Ben. Language and superdiversity. Diversities, v. 13, n. 2, p. 1-22, 2011.

\section{BUDDS, Diana. The brilliance of Alexandria Ocasio-Cortez's bold campaign} design. Disponível em: https://www.vox.com/policy-andpolitics/2018/7/2/17519414/ocasio-cortez-campaign-design-campaign-posters-tandembranding. Acesso em: 11 abr. 2020.

CAMPOS, Bianca. Colisão de identidades, culturas e linguagem: um estudo etnográfico em uma comunidade de descendentes de russos. 2015. 171 f. Dissertação (Mestrado em Linguística) - Programa de Pós- Graduação em Linguística, Universidade Federal de Santa Catarina, Florianópolis, 2015.

CANAGARAJAH, Suresh. Translingual practice: global Englishes and cosmopolitan relations. New York: Routledge. 2013.

CANAGARAJAH, Suresh. Translingual practice as spatial repertoires: expanding the paradigms beyond structuralist orientations. Applied Linguistics, v. 39, n. 1, p. 31-54, 2018.

CAVALCANTI, Marilda Couto. Estudos sobre educação bilíngue e escolarização em contextos de minorias linguísticas no Brasil. DELTA, São Paulo, v. 15, n. especial, p. 385-417, 1999.

CAVALCANTI, Marilda Couto.; BORTONI-RICARDO, Stela. Maris. (orgs.)

Transculturalidade, Linguagem e Educação. Campinas: Mercado de Letras, 2007. 
CAVALCANTI, Marilda Couto. Educação linguística na formação de professores de línguas: intercompreensão e práticas translíngues. In: MOITA LOPES, L. P. (org.). Linguística aplicada na modernidade recente: Festschrift para Antonieta Celani. São Paulo: Parábola, 2013. p. 211-226.

CREESE, Angela; BLACKLEDGE, Adrian. Translanguaging in the bilingual classroom: a pedagogy for learning and teaching? The Modern Language Journal, v. 94, n. 1, p. 103-115, 2010.

GARCEZ, Pedro de Moraes. Quem é estudante falante de português em famílias de origem brasileira em Toronto, Canadá? questões de classe. Linguagem em (Dis)curso - LemD, Tubarão, SC, v. 18, n. 3, p. 729-749. 2018.

GARCÍA, Ofelia. Bilingual education in the 21st century: a global perspective. Malden, MA and Oxford: Basil/Blackwell, 2009.

GARCÍA, Ofelia; WEI, Li. Translanguaging: language, bilingualism and education. London: Palgrave, 2014.

GREUEL, Izabel. "Falar é bom, mas entender, entender o que a professora tá falando (.) daí é outra coisa": um estudo etnográfico sobre as práticas de linguagem dos imigrantes haitianos em uma escola pública do município de Blumenau-SC. 2018. 178 f. Dissertação (Mestrado em Linguística). Universidade Federal de Santa Catarina, 2018 .

GUEROLA, Carlos Maroto. Às vezes tem pessoas que não querem nem ouvir, que não dão direito de falar pro indígena: a reconstrução intercultural dos direitos humanos linguísticos na escola Itaty da aldeia guarani do Morro dos Cavalos. 2012. 184 f. Dissertação (Mestrado em Linguística). Universidade Federal de Santa Catarina, 2012.

GUEROLA, Carlos Maroto. "Se nós não fosse guerreiro, nós não existia mais aqui”: Ensino-aprendizagem de línguas para fortalecimento da luta guarani, kaingang e laklãnõ-xokleng. 2017. 442 f. Tese (Doutorado em Linguística). Universidade Federal de Santa Catarina, Florianópolis, 2017.

HELLER, Monica; McELHINNY, Bonnie. Language, capitalism, colonialism: toward a critical history. Toronto: University of Toronto Press, 2017.

JACQUEMET, Marco. Transidiomatic practices: language and power in the age of globalization. Language \& Communication, v. 3, n. 25, p. 257-277, 2005.

LUCENA, Maria Inêz Probst; CAMPOS, Bianca. Dinâmicas sociolinguísticas e culturais de inclusão/exclusão de alunos descendentes de imigrantes russos no Sul do Brasil. Linguagem em (Dis)curso (online) ,v. 18, n. 3, p. 715-728, 2018.

MAHER, Terezinha Machado. Do casulo ao movimento: a suspensão das certezas na educação bilíngue e intercultural. In: BORTONI-RICARDO, S. M.; CAVALCANTI, 
M. C. (orgs.). Transculturalidade, Linguagem e Educação. Campinas: Mercado de Letras, 2007. p. 67-94.

MAHER, Terezinha Machado. Ecos da resistência: políticas linguísticas e línguas minoritárias no Brasil. In: NICOLAIDES, C.; SILVA. K. A.; TÍLIO, R.; ROCHA, C. H. (orgs.). Política e políticas linguísticas. São Paulo: Pontes, 2013. p. 117-134.

MENEZES DE SOUZA, Lynn Mario. Para uma redefinição de letramento crítico: conflito e produção de significação. In: MACIEL, R. F.; ARAÚJO, V. A. (orgs.).

Formação de professores de línguas: ampliando perspectivas. Jundiaí: Pacto Editorial, 2011. p. 128-140.

MOITA LOPES, Luiz Paulo. (org.). Por uma Lingüística Aplicada Indisciplinar. São Paulo: Parábola, 2006.

MOITA LOPES, Luiz Paulo da. Introdução. Fotografias da Linguística Aplicada brasileira na modernidade recente: contextos escolares. In: MOITA LOPES, L. P. Linguística aplicada na modernidade recente: Festschrift para Antonieta Celani. São Paulo: Parábola, 2013a. p. 15-37.

MOITA LOPES, Luiz Paulo da. O Português no Século XXI: Cenário Geopolítico Brasileiro. São Paulo: Parábola. 2013b.

MONTE MOR, Walkyria. Multi, trans e plural: discutindo paradigmas. Prefácio. In: TAKAKI, N. H.; MACIEL, R. F. (orgs). Letramentos em terra de Paulo Freire. Campinas: Pontes, 2017. p. 9-22.

OLIVEIRA, Denise Pimenta; NASCIMENTO, André Marques.Translinguajamento: pensando entre línguas a partir de práticas e metadiscursos de docentes indígenas em formação superior. Revista Digital dos Programas de Pós-Graduação do

Departamento de Letras e Artes da UEFS, Feira de Santana, v. 18, n. 3, p. 254-266, set.-dez. 2017.

OTHEGUY, Ricardo.; GARCÍA, Ofelia.; REID, Wallis. A translanguaging view of the linguistic system of bilinguals. Applied Linguistics Review, v. 10, n. 4, p. 625-651, 2019. Disponível em: https://www.degruyter.com/view/journals/alr/10/4/articlep625.xml Acesso em: 16 maio 2019.

PENNYCOOK, Alastair. Language as a local practice. Abingdon: Routledge, 2010.

PENNYCOOK, Alastair. Mobile times, mobile terms: The trans-super-poly-metro movement. In: COUPLAND, N. (ed.). Sociolinguistics: theoretical debates. Cambridge: Cambridge University Press, 2016. p. 201-206.

PRATT, Mary Louise. Utopias Linguísticas. Trabalhos em Linguística Aplicada, v. 52, n. 2, p. 437-459, 2013 [1987]. 
RAJAGOPALAN, Kanavilil. Linguagem, o santo graal da linguística. In: SIGNORINI, I. (org.). Situar a linguagem. São Paulo: Parábola, 2008. p. 15-38.

SCHLATTER, Margarete; GARCEZ. Pedro. Línguas adicionais na escola: aprendizagens colaborativas em Inglês. Erechim: Edelbra, 2012.

SIGNORINI, Inês.; CAVALCANTI, Marilda Couto. (orgs.). Linguística Aplicada e Transdisciplinaridade. Campinas, SP: Mercado de Letras, 1998.

SIGNORINI, Inês. Lingua(gem) e identidade: elementos para uma discussão no campo aplicado. Campinas: Mercado de Letras, 1998.

SIGNORINI, Inês. Por uma teoria da desregulamentação lingüística. In: Bagno, M. (org.). Lingüística da norma. São Paulo: Loyola, 2002. p. 93-125.

SIGNORINI, Inês. Questão da língua legítima na sociedade democrática: um desafio para a Linguística Aplicada contemporânea. In: MOITA LOPES, L. P. (org.). Por uma Lingüística Aplicada Indisciplinar. São Paulo: Parábola, 2006. p. 169-189.

SIGNORINI, Inês. Política, língua portuguesa e globalização. In: MOITA LOPES, Luiz Paulo. O Português no Século XXI: Cenário Geopolítico Brasileiro. São Paulo: Parábola. 2013. p. 74- 100.

SIGNORINI, Inês. Por que o estudo das interfaces do português contemporâneo é relevante para o campo aplicado dos estudos da língua(gem). Linguagem em (Dis)curso, v. 18, n. 3, p. 665-672, set./dez. 2018.

WEI, Li. Translanguaging as a theory of practice. Applied Linguistics, v. 39, n. 1, p. 930, 2018. Disponível em: https://doi.org/10.1093/applin/amx039. Acesso em: 30 abril, 2019.

YIP, Joanna, GARCÍA, Ofelia. Translinguagens: recomendações para educadores. Iberoamérica Social: revista-red de estudios sociales, v. IX, p. 164-177. Disponível em: https://docplayer.com.br/75339069-Translinguagens-recomendacoes-paraeducadores.html. Acesso em: 12 maio 2021.

Recebido em: 12 de julho de 2021 Aceito em: 20 de outubro de 2021 Publicado em novembro de 2021

Maria Inêz Probst Lucena E-mail: lucena.inez@gmail.com ORCiD: https://orcid.org/0000-0001-7579-5758 